\title{
Wound Healing Activity of Opuntia ficus-indica Fixed Oil Formulated in a Self-Nanoemulsifying Formulation
}

\author{
Abdulrahman E Koshak,' \\ Mardi M Algandaby, 2,3 \\ Mohammad I Mujallid, ${ }^{3}$ \\ Ashraf B Abdel-Naim, ${ }^{4}$ \\ Nabil A Alhakamy, (iD) ${ }^{5}$ \\ Usama A Fahmy, ${ }^{5}$ Anas Alfarsi, ${ }^{5}$ \\ Shaimaa M Badr-Eldin, 5,6 \\ Thikryat Neamatallah, (iD) ${ }^{4}$ \\ Mohammed Z Nasrullah, ${ }^{4}$ \\ Hossam M Abdallah, (iD) ${ }^{1,7}$ \\ Ahmed Esmat ${ }^{8,9}$ \\ 'Department of Natural Products and \\ Alternative Medicine, Faculty of Pharmacy, \\ King Abdulaziz University, Jeddah, Saudi \\ Arabia; ${ }^{2}$ Medicinal Plants Research Group, \\ Deanship of Scientific Research, King \\ Abdulaziz University, Jeddah, Saudi Arabia; \\ ${ }^{3}$ Faculty of Science, Department of \\ Biological Sciences, King Abdulaziz \\ University, Jeddah, Saudi Arabia; \\ ${ }^{4}$ Department of Pharmacology and \\ Toxicology, Faculty of Pharmacy, King \\ Abdulaziz University, Jeddah, Saudi Arabia; \\ ${ }^{5}$ Department of Pharmaceutics, Faculty of \\ Pharmacy, King Abdulaziz University, Jeddah, \\ Saudi Arabia; ${ }^{6}$ Department of \\ Pharmaceutics and Industrial Pharmacy, \\ Faculty of Pharmacy, Cairo University, Cairo, \\ Egypt; ${ }^{7}$ Department of Pharmacognosy, \\ Faculty of Pharmacy, Cairo University, Cairo, \\ Egypt; ${ }^{8}$ Department of Pharmacology, \\ Faculty of Medicine, King Abdulaziz \\ University, Jeddah, Saudi Arabia; \\ ${ }^{9}$ Department of Pharmacology and \\ Toxicology, Faculty of Pharmacy, Ain Shams \\ University, Cairo, Egypt
}

Correspondence: Hossam M Abdallah Department of Natural Products and Alternative Medicine, Faculty of Pharmacy, King Abdulaziz University, Jeddah, 21 589,

Saudi Arabia

Tel +966544733 I I0

Email hmafifi@kau.edu.sa
Introduction: Delayed wound healing represents a common health hazard. Traditional herbal products have been often utilized to promote wound contraction. The current study aimed at assessing the wound healing activity of Opuntia ficus-indica seed oil (OFI) and its self-nanoemulsifying drug delivery system (OFI-SNEDDS) formula in a rat model of fullthickness skin excision.

Methods: Based on droplet size, an optimized OFI-SNEDDS formula was prepared and used for subsequent evaluation. Wound healing activity of OFI and OFI-SNEDDS was studied in vivo.

Results: The optimized OFI-SNEDDS formula droplet size was $50.02 \mathrm{~nm}$. The formula exhibited superior healing activities as compared to regular OFI seed oil-treated rats at day 14 of wounding. This effect was further confirmed by histopathological examinations of H\&E and Masson's Trichrome-stained skin sections. Moreover, OFI-SNEDDS showed the highest antioxidant and anti-inflammatory activities as compared to OFI seed oil-treated animals. Both OFI and OFI-SNEDDS significantly enhanced hydroxyproline skin content and upregulated Col1A1 mRNA expression, accompanied by enhanced expression of transforming factor-beta (TGF- $\beta$ ). Further, OFI-SNEDDS improved angiogenesis as evidenced by increased expression of vascular endothelial growth factor (VEGF).

Conclusion: OFI possesses wound healing properties that are enhanced by self-emulsification of the oil into nano-droplets. The observed activity can be attributed, at least partly, to its anti-inflammatory, pro-collagen and angiogenic properties.

Keywords: Opuntia ficus-indica, SNEDDS, wound healing, TGF- $\beta$, VEGF, rats

\section{Introduction}

Wounds pose a rising threat to global health and economy. Wounds resulting from surgery and diabetic are the most difficult to treat among chronic wounds. Also, delayed healing of acute wounds could have a significant impact on the quality of patients' life. It might cause loss of function and mobility. ${ }^{1,2}$ In Europe and USA, there is a substantial demand for wound care products. In 2014, annual global cost for wound care was estimated to be about $\$ 2.8$ billion. $^{3}$ In 2019 , a systematic review of studies on global prevalence of chronic wounds found that chronic wounds of varied etiologies had a combined prevalence of 2.21 per 1000 people. Most chronic wounds are made up by chronic leg ulcers. ${ }^{4}$ Wound could be defined as the disruption of a living tissue with respect to cellular, anatomical, and functional continuity. ${ }^{5}$ When the skin is cut, torn, or pierced, it is named an open wound. 
On the other hand, a closed wound results from blunt force trauma leading to a bruise, while the burn wounds are produced by heat, fire, corrosives, radiation, electricity, or even sunlight. ${ }^{6}$

Wound healing represents a complex of intricate cascade of cellular and biochemical events in order to restore tissue integrity - both structural and functional - as well as recover the strength of damaged tissues. This encompasses incessant cell-cell and cell-matrix interactions, allowing overlapping phases to proceed such as inflammation, wound contraction, re-epithelialization, tissue remodeling, and granulation tissue formation with angiogenesis. ${ }^{7}$ The stages of wound healing typically progress in an anticipated and timely manner. If they do not, inappropriate healing may lead to a pathological scarring as "keloid scar" or a chronic wound as a "venous ulcer". ${ }^{8}$ The aim of wound care is to stimulate wound healing appropriately in an optimum time with minimal discomfort and scarring to the patient. It has to occur in a physiological environment that favors tissue repair and regeneration. ${ }^{6}$

Medicinal plants contain a wealth of natural compounds that showed wound healing properties. ${ }^{9}$ Traditional herbal preparations have been often used for wound healing purposes, related to different skin disorders. These preparations could generally act through disinfection, debridement, and providing a suitable environment for supporting the natural progression of healing. ${ }^{10}$ Interestingly, a high percentage of world population still depends on traditional medicines for wounds management considering it as an economical option to treat wounds. ${ }^{11}$ Phytochemical investigations of traditionally used medicinal plants showed several useful classes of phytochemical compounds like alkaloids, phenolics, tannins, terpenes, steroids, flavonoids, glycosides, and fatty acids. These phytochemicals may have a potential role in the management of wounds via enhancing blood clotting, fighting infection and accelerating the healing of wounds. ${ }^{12}$ Opuntia ficus-indica (OFI), a medicinal plant that belongs to the family Cactaceae has been used traditionally for several conditions including wound healing. ${ }^{13}$ Several extracts of different parts of OFI, including stems and cladodes, have shown promising wound healing properties in animal models. ${ }^{14,15}$ Also, OFI seed oil from Tunisia showed a potential for wound healing in rats. ${ }^{16}$ The oil from OFI seed grown in Saudi Arabia contains mainly palmitic acid (10.6\%), linoleic acid (5.9\%), oleic acid (8.1\%) and $\beta$-sitosterol $(24.9 \%)$ and showed anti-inflammatory properties in animal models. ${ }^{17}$ However, Saudi OFI seed oil was not investigated for its potential of wound healing. Selfnanoemulsifying drug delivery systems (SNEDDSs) are expected to promote drug bioavailability and poses better pharmacological activity. ${ }^{18}$ Therefore, the aim of current study was to investigate the wound healing activity of Opuntia ficus-indica (OFI) seed oil and the possibility of enhancing this activity using self-nanoemulsifying (OFISNEDDS) drug delivery system in a full-thickness skin excisional model in rats.

\section{Materials and Methods Chemicals}

Polyethylene glycol 200 and tween 80 were purchased from Sigma Aldrich (MO, USA).

\section{Plant Material and Oil Preparation}

Seeds of Opuntia ficus-indica (L.) Mill. (OFI) were purchased from Al-Baha governorate, Saudi Arabia and was identified by Dr. Emad Al-Sharif (Plant Ecology, Dept. of Biology, Faculty of Science \& Arts, Khulais, King Abdulaziz University, KSA). A sample was kept in the herbarium of Faculty of Pharmacy, King Abdulaziz University (OFI-1241). One kilogram of the seeds was extracted with hexane using Soxhlet apparatus as previously reported. ${ }^{17}$

\section{Chemical Investigation of Oil}

Oil sample obtained by extraction was analyzed for their contents using an Agilent 7820A gas chromatography system coupled to Agilent 5975 series quadrupole mass spectrometer working in EI mode and resolved on a Termo BPX70 column $(50 \mathrm{~m} \times 250 \mu \mathrm{m} \times 0.25 \mu \mathrm{m})(\mathrm{J} \& \mathrm{~W}$ Scientific, USA) as previously reported. ${ }^{17}$

\section{Preparation of OFI-SNEDDS}

OFI seed oil (200 mg) was previously analyzed for its chemical composition and standardized as described previously. SNEDDS were prepared via mixing the specified quantities of OFI, Tween 20, and PEG 200 at $40^{\circ} \mathrm{C}$. The blend was subjected to vortex for $60 \mathrm{~s}$ to allow for homogenization. ${ }^{17,19}$ The effectiveness of emulsification was assessed by adding $100 \mathrm{mg}$ of each blend to $50 \mathrm{~mL}$ double distilled water, followed by magnetic stirring at 37 $\pm 0.5^{\circ} \mathrm{C}^{20,21}$ 


\section{Optimization of OFI-SNEDDS Using D-Optimal Mixture Design}

A three-component mixture system was optimized using D-optimal mixture design. The explored mixture systems include oil (OFI), surfactant (Tween 20), and cosurfactant (PEG 200). The components' percentages in each mixture were summed up to $100 \%$. The used percentages, selected on the basis of preliminary study results (data not shown), were as follows: oil; OFI $\left(\mathrm{X}_{1}, 10-40 \%\right)$, surfactant; Tween $20\left(\mathrm{X}_{2}, 30-50 \%\right)$, and cosurfactant; PEG $200\left(\mathrm{X}_{3}\right.$, 20-40\%). Average globule size of the prepared system (Y) was studied as response. The experimental runs were generated by Design-Expert ${ }^{\mathbb{B}}$ Software Version 11 (StatEase Inc, Minneapolis, Minnesota, USA). The design points set by the software included combinations at vertices, edge centers, and edge thirds, and reinforced by check blends and an overall centroid. Accordingly, the proposed design consisted of 20 runs that included 5 replicate points and 4 center points (Table 1). The measured size was fitted to various sequential models. Fit statistics criteria were calculated to pick up the best fitting

Table I The Composition of OFI-SNEDDSs Prepared Based on D-Optimal Mixture Design and Their Measured Globule Size

\begin{tabular}{|c|c|c|c|c|}
\hline \multirow[t]{2}{*}{$\begin{array}{l}\text { Run } \\
\#\end{array}$} & \multicolumn{3}{|c|}{$\begin{array}{c}\text { Mixture Components } \\
\text { Percentages* }\end{array}$} & \multirow[t]{2}{*}{$\begin{array}{c}\text { Globule Size } \\
\text { (nm) }\end{array}$} \\
\hline & $\begin{array}{l}\text { OFI; } \\
\mathbf{X}_{1}\end{array}$ & $\begin{array}{l}\text { Tween 20; } \\
\quad x_{2}\end{array}$ & $\begin{array}{l}\text { PEG 200; } \\
x_{3}\end{array}$ & \\
\hline I & 40 & 40 & 20 & 168 \\
\hline 2 & 30 & 50 & 20 & 176 \\
\hline 3 & 26.67 & 36.67 & 36.66 & 152 \\
\hline 4 & 23.33 & 43.33 & 33.34 & 130 \\
\hline 5 & 30 & 40 & 30 & 162 \\
\hline 6 & 20 & 50 & 30 & 155 \\
\hline 7 & 40 & 40 & 20 & $|7|$ \\
\hline 8 & 10 & 50 & 40 & 50 \\
\hline 9 & 30 & 50 & 20 & 188 \\
\hline 10 & 40 & 30 & 30 & 245 \\
\hline 11 & 26.67 & 46.67 & 26.66 & 154 \\
\hline 12 & 30 & 40 & 30 & 165 \\
\hline 13 & 30 & 30 & 40 & 228 \\
\hline 14 & 40 & 35 & 25 & 218 \\
\hline 15 & 40 & 30 & 30 & 248 \\
\hline 16 & 30 & 40 & 30 & 177 \\
\hline 17 & 30 & 40 & 30 & 180 \\
\hline 18 & 20 & 40 & 40 & 109 \\
\hline 19 & 10 & 50 & 40 & 53 \\
\hline 20 & 30 & 30 & 40 & 223 \\
\hline
\end{tabular}

Note: *The percentages of each run are summed up to 100. polynomial model. The effect of the components' percentages on the globule size was evaluated by analysis of variance (ANOVA) at $P<0.05$. The composition of the optimal formulation was predicted by numerical optimization, and desirability function was computed. The goal of the optimization process was to minimize the globule size of the formulated system.

\section{Determination of OFI-SNEDDS Globule} Size

Dynamic light scattering technique was employed to measure OFI-SNEDDS globule size using a Nano-ZS particle size analyzer (Malvern Instrument, Worcestershire, UK). OFI SNEDDS sample was appropriately diluted with deionized water and vortexed for $1 \mathrm{~min}$ prior to measurement. ${ }^{22}$

\section{Preparation of and Characterization of OFI- Hydroxypropyl Methylcellulose Gel}

After formulae preparation, the optimized OFI-SNEDDS formula as well as raw OFI seed oil were poured in $2 \%$ hydroxypropyl methylcellulose (HPMC) solution and mixed using magnetic stirrer for $30 \mathrm{~min}$ before experiments. The final concentration of the prepared gels was $5 \% \mathrm{~W} / \mathrm{V}$ of OFI seed oil and an equivalent weight of the OFI seed oil of the optimized formula. The prepared gel was characterized for its viscosity using cone and plate viscometer (DV2T, Ametek Brookfield, USA) at ambient temperature.

\section{Animals}

Fifty male Wistar rats (190-220 g) were utilized in the existing study, conducted at the Animal Facility, Faculty of Pharmacy, King Abdulaziz University, Jeddah, Saudi Arabia. Rats were kept on a 12-h light-dark cycle and a persistent temperature of $22 \pm 2{ }^{\circ} \mathrm{C}$. The experimental protocol involving animals and their care was conducted in compliance with the Association for Assessment and Accreditation of Laboratory Animal Care (AAALAC) international guidelines and approved in advance by Research Ethics Committee, Faculty of Pharmacy, King Abdulaziz University (Approval \# PH-121-41).

\section{Ex vivo Skin Permeation Studies}

The diffusion of prepared films was measured using a Franz diffusion cell apparatus (Microette Plus; Hanson Research, Chatsworth, CA, USA). ${ }^{23}$ After hair removal, 
skin $\left(2 \mathrm{~cm}^{2}\right)$ was collected from the abdominal area of male rats for use as a membrane. Each diffusion cell contained a donor and receptor chamber separated by a film. Phosphate-buffered saline was used as the receptor medium ( $\mathrm{pH} 7.2$ ), temperature was held at $32 \pm 0.5^{\circ} \mathrm{C}$ and the stirring rate was $400 \mathrm{rpm}$. At $0.5,1,2,4,8,12$ and 24 $\mathrm{h}$, the autosampler obtained aliquots, which were then analyzed using HPLC. The in vitro skin permeation data were used to measure skin permeation parameters such as steady-state transdermal flux (Jss), diffusion coefficient (D) and permeability coefficient (Kp). As a function of time, the total volume of OFI permeated per unit area of skin was plotted. The autosampler collected aliquots at $0.5,1,2,4,8,12$ and $24 \mathrm{~h}$, and these were then analyzed by HPLC. $^{24}$ Skin permeation parameters, steady-state transdermal flux (Jss), permeability coefficient (Kp) and diffusion coefficient (D).

\section{Wounding by Excision and Animal Treatment}

Rats were anesthetized and the dorsal surface of each rat was shaved and swapped with antiseptic solution $(70 \%$ ethanol). A full-thickness acute excision circle $(1 \mathrm{~cm}$ in diameter) was engraved on each rat's dorsal surface. Lidocaine hydrochloride (2\%) containing 1:80,000 epinephrine $(4.4 \mathrm{mg} / \mathrm{kg})$ was injected subcutaneously near the wound area immediately after wounding to reduce pain. With the exception of untreated animals, an amount of $0.5 \mathrm{~g}$ of each assigned treatment was applied to wounded area in each animal. The wounds were then covered with Vaseline Gauzes dressing and was changed once daily.

Wounded rats were arbitrarily alienated into five groups (10 each) as follows:

Group 1: Untreated control rats with no treatment.

Group 2: Treated topically once daily with the plain vehicle (mixture of polyethylene glycol 200 and tween 80 in 1:1 ratio) in the wound area.

Group 3: Treated topically once daily with regular OFI seed oil in the wound area.

Group 4: Treated topically once daily with OFISNEDDS in the wound area.

Group 5: Positive control and treated topically once daily with Mebo $^{\circledR}$ ointment, Julfar, UAE ( $\beta$-sitosterol, berberine, and baicalin as active ingredients in a base of beeswax and sesame oil) in the wound area.
All treatments continued for 14 days. Wounds were assessed and photographed at days 0,3,7,10 and 14. At day 7 , four animals from each group were sacrificed by decapitation and the skin in the wound area was dissected out and kept in $10 \%$ formalin/saline. At day 14 , the rest of animals in all groups were sacrificed by ether overdose and the skin in the wound area was dissected. Part of the skin from each animal was kept in $10 \%$ neutral formalin and the other part was flash frozen in liquid nitrogen and kept in $-80^{\circ} \mathrm{C}$ for further analyses.

\section{Wound Measurement}

The diameter of each wound was measured using a Vernier Caliper $(0-150 \mathrm{~mm})$; then, the percentage of wound contraction was calculated based on the following formula:

Wound contraction $\%=\frac{\begin{array}{c}\text { Day } 0 \text { wound diameter } \\ \text { Day } 14 \text { wound diameter }\end{array}}{\text { Day } 0 \text { wound diameter }} \times 100$

\section{Preparation of Tissue Homogenate}

Collected skin specimens were carefully rinsed with ice-cooled saline, gently blotted between filter papers and weighed. Ten percent of homogenates were prepared in ice-cooled phosphate-buffered saline (PBS, $50 \mathrm{mM}$ potassium phosphate, $\mathrm{pH}$ 7.4) followed by centrifugation at $10,000 \mathrm{~g}$ for $20 \mathrm{~min}$ at $4^{\circ} \mathrm{C}$. The supernatant was used for the estimation of malondialdehyde (MDA), reduced glutathione (GSH) content, superoxide dismutase (SOD) activity and glutathione peroxidase (GPx) activity as antioxidant biomarkers. In addition, interleukin-6 (IL-6), tumor necrosis factor-alpha (TNF- $\alpha$ ) and hydroxyproline concentrations were all assessed.

\section{Histological Examination}

Wound tissues collected at days 7 and 14 were fixed in 10\% formalin/saline for $24 \mathrm{~h}$. This was followed by dehydration in serial concentrations of ethanol, cleared in xylene and embedded in paraffin. Tissues in paraffin block were sectioned ( $5 \mu \mathrm{m}$ thickness). After dewaxing, tissues were rehydrated. Some sections were stained using hematoxylin and eosin (H\&E) and the rest were stained with Masson's trichrome. Histological examination was performed by an experienced pathologist without knowledge of treatment groups. Depending on the degree of re-epithelization, granulation tissue formation, collagen deposition, inflammatory cell infiltration and wound healing phase (I, II or III) at day 7 , sections were given scores based on their abundance ranging from - to +++ . 


\section{Biochemical Analyses}

MDA, GSH, SOD, GPx, and total protein were assessed using commercially available kits (catalog \# 10009055, 703002, 706002, 703102 and 701780, respectively, Cayman ${ }^{\circledR}$ Chemical, Ann Arbor, MI, USA). Skin content of IL-6, TNF- $\alpha$ and hydroxyproline were determined using ELISA Kits (catalog \# ab100772, ab236712 and ab222941, Abcam ${ }^{\circledR}$, Cambridge, UK) as stated by the manufacturer's instructions.

\section{RT-qPCR in Excised (Healing/Healed) Tissue}

Tissues from each rat at day 14 were homogenized in an ultrasonic probe. RNA was extracted utilizing a nucleic acid extraction kit (NucleoSpin ${ }^{\circledR}$, Macherey-Nagel GmbH \& Co. KG, Duerin, Germany). The purity estimated as (A260/A280 ratio) and RNA concentration were obtained using spectrophotometry (dual-wavelength Shimadzu, Spectrophotometer, Japan). In order to construct a cDNA library, reverse transcription was performed using a High-Capacity cDNA Reverse Transcription Kit (Applied Biosystems, Foster City, CA, USA). Then, PCR amplification was completed using a Taq PCR Master Mix Kit (Qiagen, Valencia, CA, USA) using the Col1A1 (NM_053304.1) primer as well as GPADH (NM_017008.4) as a housekeeping gene. Forward/reverse nucleotide sequences of CollA1 and GAPDH were ATCAGCCCAAACCCCAAGGAGA/CGCAGGAAGGT CAGCTGGATAG and CCATTCTTCCACCTTTGATGCT/ TGTTGCTGTAGCCATATTCATTGT, respectively. After the RT-PCR run, the data were expressed in cycle threshold $(\mathrm{Ct})$. The relative quantitation (RQ) of CollA1 to GAPDH was determined according to the calculation of delta-delta $\mathrm{Ct}$ $(\Delta \Delta \mathrm{Ct})$.

\section{Immunohistochemical Detection of TGF- $\beta$ and VEFG}

Immunohistochemical (IHC) technique was utilized to detect TGF- $\beta$ and VEGF in tissue slices by labeling them with HRP that could react with a specific substrate to give a brown color in tissue. ${ }^{25}$ Briefly, tissue slices $(4 \mu \mathrm{m}$ thickness) were immunohistochemically stained with the primary rabbit antibodies to TGF- $\beta$ and VEGF (Catalog \#: ab229856 and ab53465, respectively; Abcam $^{\circledR}$, Cambridge, UK). Image quantitation was performed via image analysis software (ImageJ, 1.48a, NIH, USA), as optical density (OD) of brown-stained (positive) cells across six different areas for each rat section.

\section{Statistical Analysis}

All data are displayed as the mean \pm SD. Statistical analysis was carried out using one-way analysis of variance (ANOVA) followed by Tukey's post-hoc test. All analyses were conducted, and figures were sketched using GraphPad Prism software, version 8.00 (GraphPad Software, La Jolla, CA, USA). The level of significance was accepted as $\mathrm{p}<0.05$.

\section{Results}

\section{Droplet Size of OFI SNEDDSs}

The prepared SNEDDs showed satisfactory globule size that ranged from 50 to $248 \mathrm{~nm}$ as shown in Table 1. To ensure efficient penetration of the oil into skin layers, D-optimal design was utilized to optimize globule size of the proposed system to minimize value. The mixture design permits the exploration of changes in the globule size as a function of the relative percentages of oil, surfactant, and cosurfactant. The design included six model points representing the minimum number of runs required to estimate the coefficients of the terms in the selected model, five lack-of-fit points that can provide extra information for testing the fitting of the model, in addition to five replicate points that support the optimality and provide an estimate of pure error.

\section{Fit Statistics and Diagnostic Analysis}

The best fitting model for the globule size data was the quadratic model based on its greatest correlation (R2) and minimal predicted residual sum of square (PRESS), Table 2. Further, the predicted and the adjusted R2 were

Table 2 Model Fit Statistics of OFI-SNEDDSs Globule Size

\begin{tabular}{|l|c|c|c|c|c|c|c|}
\hline Model & Model P-value & Lack of Fit P-value & SD & $\mathbf{R}^{\mathbf{2}}$ & Adjusted R & Predicted R $^{\mathbf{2}}$ & PRESS $^{2}$ \\
\hline Linear & $<0.0001$ & $<0.0001$ & 26.41 & 0.7840 & 0.7586 & 0.6740 & $17,892.90$ \\
Quadratic & 0.0026 & 0.1207 & 8.20 & 0.9829 & 0.9767 & 0.9693 & 1686.15 \\
Special cubic & 0.4717 & 0.0983 & 8.33 & 0.9836 & 0.9760 & 0.9542 & 1859.62 \\
\hline
\end{tabular}

Abbreviations: $\mathrm{R}^{2}$, multiple correlation coefficient; PRESS, predicted residual error sum of squares. 
in rational coinciding, and the adequate precision value of 44.55 (higher than 4) verified that the possibility of model utilization to explore the experimental design space. Lack of Fit F-value of $2.44(\mathrm{P}=0.1207)$ indicates non-significance of the lack of fit in relation to the pure error. There is a probability of $12.07 \%$ that a Lack of Fit F-value might be that high ascribed to noise.

Diagnostic plots for globule size were developed to check and establish the goodness of fit of the quadratic model. Box-Cox plot for power transforms, Figure 1A, exhibits a best lambda $(\lambda)$ value of 1.06 (represented by
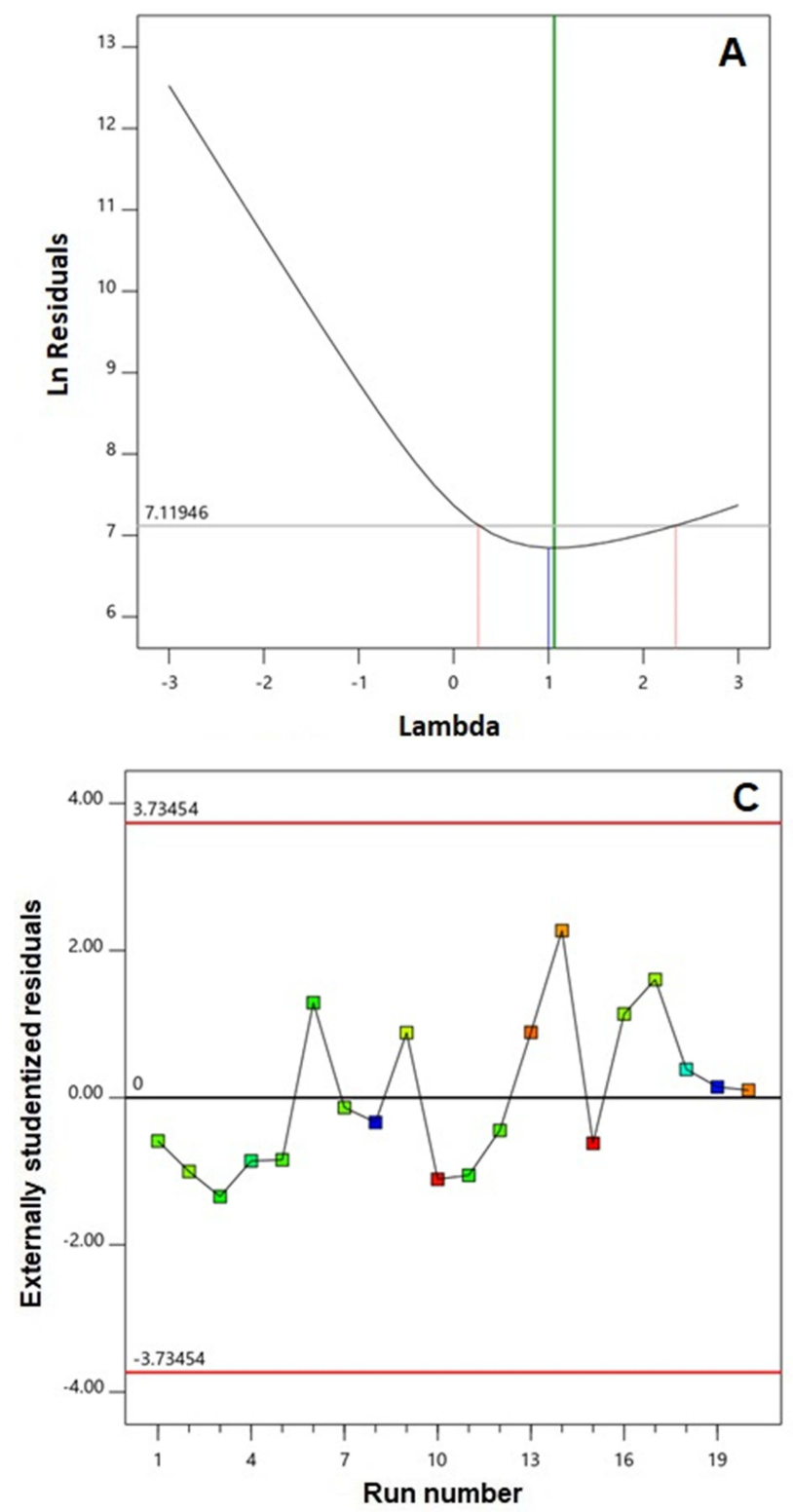

the green line). The $95 \%$ confidence interval around this $\lambda$ is computed as $0.26-2.34$ (represented by the red lines); the computed confidence interval includes the value 1 (current $\lambda$ represented by the blue line); accordingly, no specific data transformation is required. ${ }^{26}$ The waived transformation requirement is evidenced by the ratio of maximum to minimum measured globule size of 4.96 , where a ratio greater than 10 probably highlights the need for transformation. The colored points corresponding to the experimentally determined globule size in the externally studentized residuals vs predicted response plot,
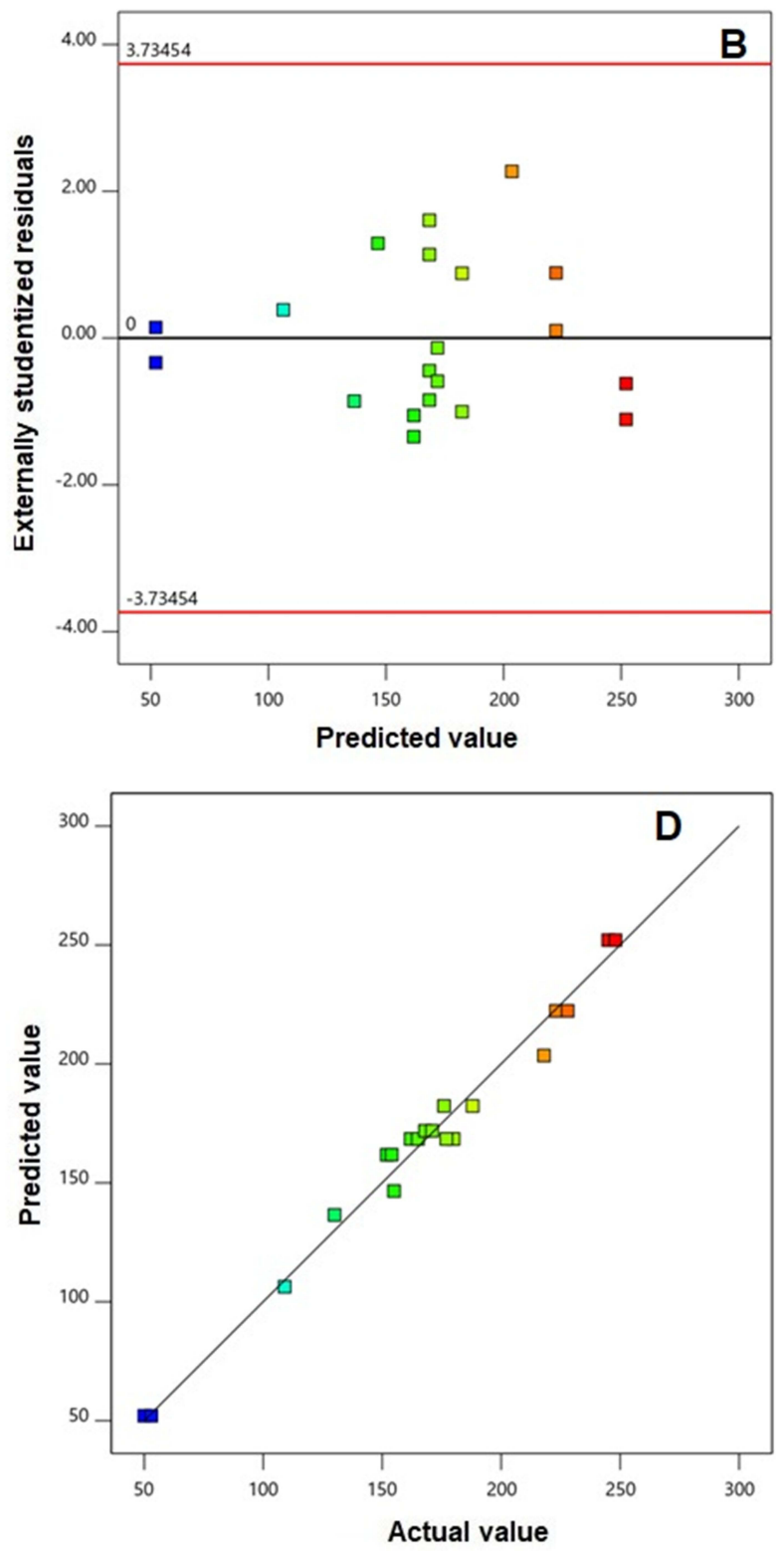

Figure I Diagnostic plots for globule size of OFI-SNEDDSs (A) Box-Cox for power transforms (B) externally studentized residuals vs predicted values (C) externally studentized residuals vs run number and (D) predicted vs actual globule sizes. 
Figure 1B, were randomly scattered within the limits indicating the absence of constant error. In addition, Figure $1 \mathrm{C}$ for the residual vs run plot displays random distribution of points, revealing that no lurking factor could affect the measured response. Further, the predicted versus actual globule size plot, Figure 1D, exhibits good linearity that reflects appropriate matching between the observed and predicted values. $^{27,28}$

\section{Influence of Mixture Components on Globule Size}

Results of statistical analysis of the effect of mixture components on OFI-SNEDDSs globule size verified that the quadratic model displays significance as evidenced by its F-value of $160.60(P<0.0001)$. The percentages of the three components of the systems were found to exert a significant influence on the globule size at $95 \%$ confidence level. In addition, the binary interactions between each two of the mixture components $\left(\mathrm{X}_{1} \mathrm{X}_{2}, \mathrm{X}_{1} \mathrm{X}_{3}\right.$, and $\left.\mathrm{X}_{2} \mathrm{X}_{3}\right)$ and the interaction between the three components $\left(\mathrm{X}_{1} \mathrm{X}_{2} \mathrm{X}_{3}\right)$ displayed also significant impact at the same significance level. The coded equation describing the quadratic model was generated as follows:

$\mathrm{Y}=52.09 \times_{1}+400.05 \times_{2}+159.44 \times_{3}-277.81 \mathrm{X}_{1} \mathrm{X}_{2}+$ 264.14 $\mathrm{X}_{1} \mathrm{X}_{3}-304.88 \mathrm{X}_{2} \mathrm{X}_{3}$

The interactive influences of the mixture components on the globule size were graphically illustrated in the two- dimensional contour and the three-dimensional surface plots, Figure 2A and B respectively. The globule size significantly increases with increasing OFI concentration, while decreases with increasing between $20\left(\mathrm{X}_{2}\right)$ and PEG $200\left(\mathrm{X}_{3}\right)$ percentages. The coefficient magnitude of the linear terms indicates that the surfactant and cosurfactant effects were more pronounced than that of the oil. The globule size increase with increasing oil concentration in SNEDDSs was previously reported and was explained based on elevated viscosity with increasing oil content, which subsequently leads to higher chance of aggregation of the system droplets. ${ }^{29,30}$

On the contrary, the mean globule size reduction at higher surfactant could be ascribed to increased area at the water-oil interface due to the build-up of surfactant particles; this could potentially lead to reduced interfacial tension and protect against droplets coalescence. ${ }^{31-33}$

\section{Prediction and Characterization of the Optimized Formulation}

Drug delivery systems optimization aims at predicting the levels of the variables that could result in a product with desired properties. The optimization process in this study aims at minimizing the globule size of the proposed OFISNEDDSs to improve the oil solubility and enhance its penetration via skin layers with consequent expected enhancement of wound healing activity. The levels of
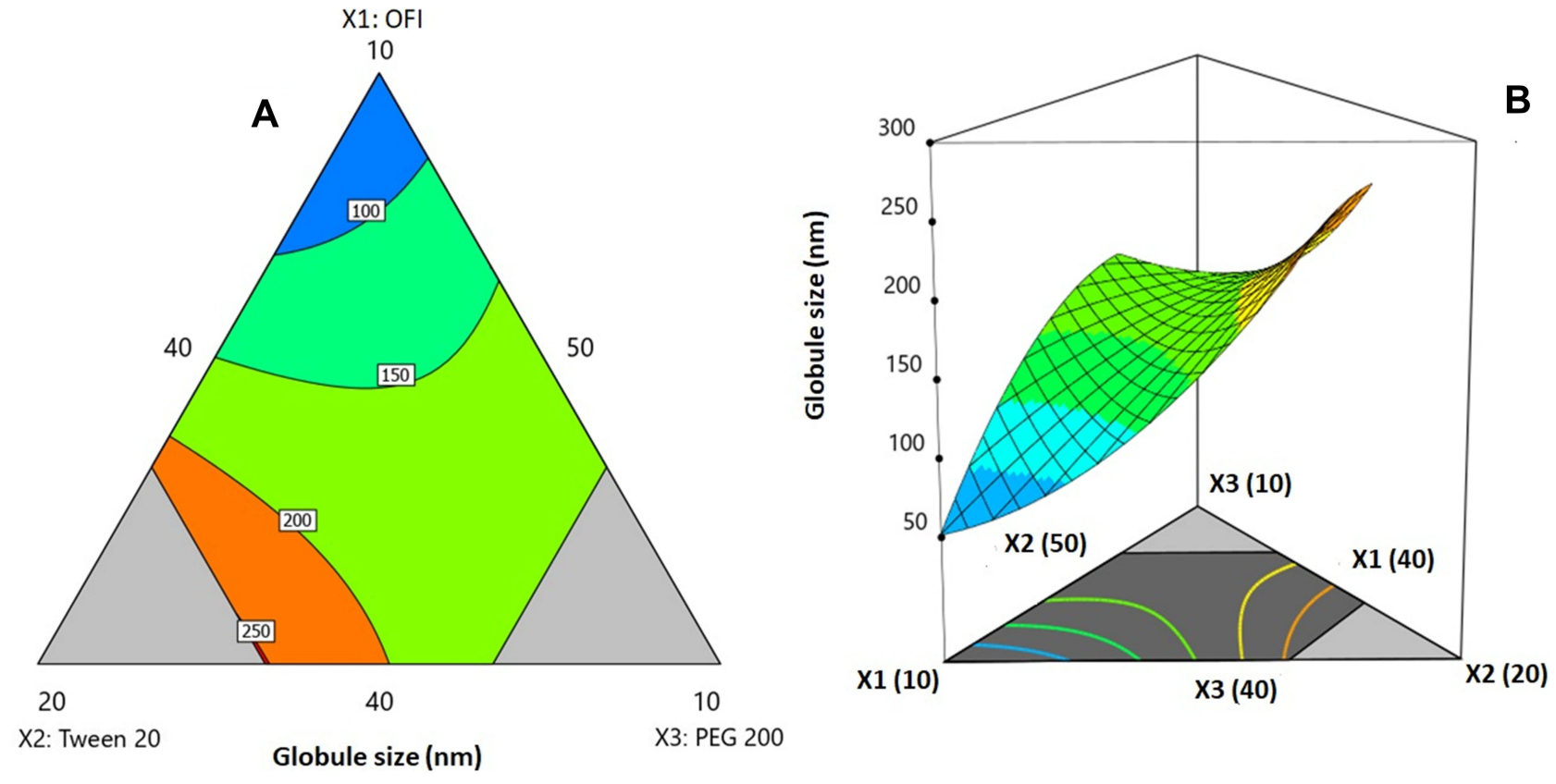

Figure 2 2D contour plot $(\mathbf{A})$ and 3D response surface plot $(\mathbf{B})$ for the influence of mixture components on the globule size of OFI-SNEDDSs. 
mixture components that yield SNEDDS with minimized globule size were predicted by numerical optimization as follows: OFI, Tween 20 and PEG 200 percentages of 10, 50 and $40 \%$, respectively. The software predicted that the proposed formulation could achieve globule size of 52.09 nm with a desirability of 0.989 . The percentage relative error between predicted size and observed one (53.39) was $2.49 \%$. This relatively low error percentage affirms the credibility of the optimization technique. The measured polydispersity index (PDI) was 0.199 with zeta potential of $-11.2 \pm 2.1$. The viscosity of the gel incorporating the optimized formulation was $48.3 \pm 2.1 \mathrm{cp}$. The proposed formulation was subjected to further wound healing activity studies.

\section{Permeation Study}

Comparative permeation profiles of optimized OFISNEDDS and unprocessed OFI gel are depicted in Figure 3. There was a dramatic rapid diffusion of OFI $(\sim 30 \%)$ after $2 \mathrm{~h}$ from the optimized formula; diffusion from OFI-OIL did not exceed $13 \%$ after $2 \mathrm{~h}$. The optimized formulation showed significantly $(\mathrm{P}<0.05)$ enhanced transdermal flux $(0.22 \pm 2.12 \mathrm{ng} / \mathrm{cm} 2 \cdot \mathrm{h})$ across rat skin compared with OFI-OIL $(0.17 \pm 1.32 \mathrm{ng} / \mathrm{cm} 2 \cdot \mathrm{h})$. Skin permeation parameters which were calculated from the skin permeation data are shown in Table 3, that are attributed to the effect of surfactant and co-surfactants, which acts as penetration enhancer in skin by increasing the fluidity of cell membrane lipids and decreasing the density of cell membrane lipids. The improved diffusion of OFI-SNEDDS may also have been facilitated by fusion

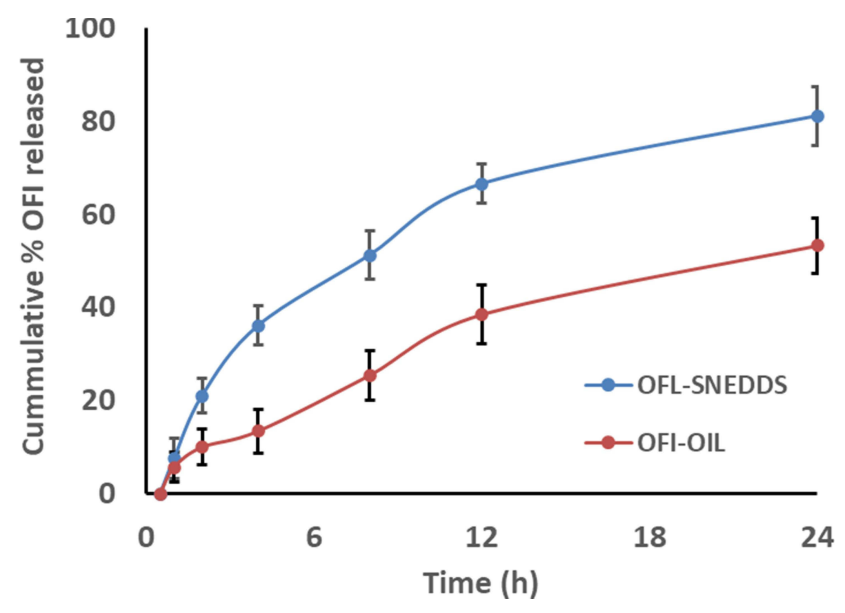

Figure 3 Percentage of cumulative OFI permeation from OFI-SNEDDS gel and from OFI-OIL gel through abdominal rat skin. of nano-globules with skin lipids, thereby facilitating OFISNEDDS permeation into deep skin layers.

\section{Assessment of Wound Healing}

Topical application of OFI seed oil or OFI-SNEDDS showed a slight nonsignificant reduction in wounds until day 3. At day 7, OFI-SNEDDS significantly expedited wound healing as compared to untreated and vehicle-treated control groups. At day 14, wounds exposed to OFI-SNEDDS showed nearly complete healing. It is noteworthy to report that the prepared OFISNEDDS formula exhibited superior healing activities as compared to the positive control group (Figure 4A). Assessment of wound contraction percentage indicated that animals treated with OFI-SNEDDS showed significantly higher wound contractions (Figure 4B).

\section{Histopathological Examination of Wound Tissues Stained with H \& E and Masson's Trichrome (MT)}

H\&E staining of skin tissues collected at day 7 from untreated and vehicle-treated controls (negative controls) showed marked edema, inflammatory and proliferating thin-walled small blood vessels with proliferating fibroblasts (granulation tissue; GT) extending to underlying fat (Figure 5A). MT staining showed excess immature thick collagen bundles in superficial and deep wound areas (Figure 5B). Skin sections from OFI-treated animals showed small wound areas with mild inflammation, markedly proliferating dilated congested blood vessels and moderate collagen deposition (CD) in the underlying muscles and covered with completely epithelialized superficial layer (Figure 5A). MT staining of the same tissues revealed moderate amount of thin mature collagen bundles in superficial and deep wound areas (Figure 5B). These histological changes were comparable to those observed in control animals.

At day 14, H\&E staining of skin sections obtained from untreated and vehicle-treated negative control groups showed areas of ulcer with underlying small wound with moderate inflammation, scattered dilated congested blood vessels, excess collagen, and early re-epithelialization (RE) of the superficial layers (Figure 5C). MT staining of the same tissues revealed moderate amounts of mature thin collagen bundles more in superficial wound areas (Figure 5D). Examination of OFI-SNEDDS groups exhibited superior wound healing properties as compared to negative controls, OFI seed oil and positive groups. H\&E staining indicated that skin sections obtained from OFI- 
Table 3 Skin Permeation Parameters of OFI-Oil and OFI-SNEDDS Through Rat Abdominal Skin

\begin{tabular}{|l|c|c|c|}
\hline Parameter & Unit & OFI -OIL & OFI-SNEDDS \\
\hline Steady-state flux & $\mathrm{ng} / \mathrm{cm}^{2} \mathrm{~h}$ & $0.17 \pm 1.32$ & $0.22 \pm 2.12^{*}$ \\
Permeability coefficient & $\mathrm{cm} / \mathrm{h}$ & $0.00069 \pm 0.00 \mathrm{I}$ & $0.00089 \pm 0.003$ \\
Diffusion coefficient (D) & $\mathrm{cm}^{2} / \mathrm{h}$ & $0.00056 \pm 0.002$ & $0.001 \mathrm{I} \pm 0.00 I^{*}$ \\
\hline
\end{tabular}

Note: *Significant variance $(\mathrm{P}$-value $<0.05)$.

SNEDDS group showed big scar with few proliferating congested blood vessels more in superficial and deep areas, excess collagen, and covered by completely epithelialized epidermis (Figure 5C). In line with these findings,
MT staining showed moderate amount of mature thick collagen bundles in superficial and deep wound areas (Figure 5D). Semi-quantitation of histological findings at day 7 indicates that skin tissues of OFI-SNEDDS-treated
A

\section{Untreated Control}

\section{Vehicle- \\ Treated Control}

OFI

OFISNEDDS

Positive Control
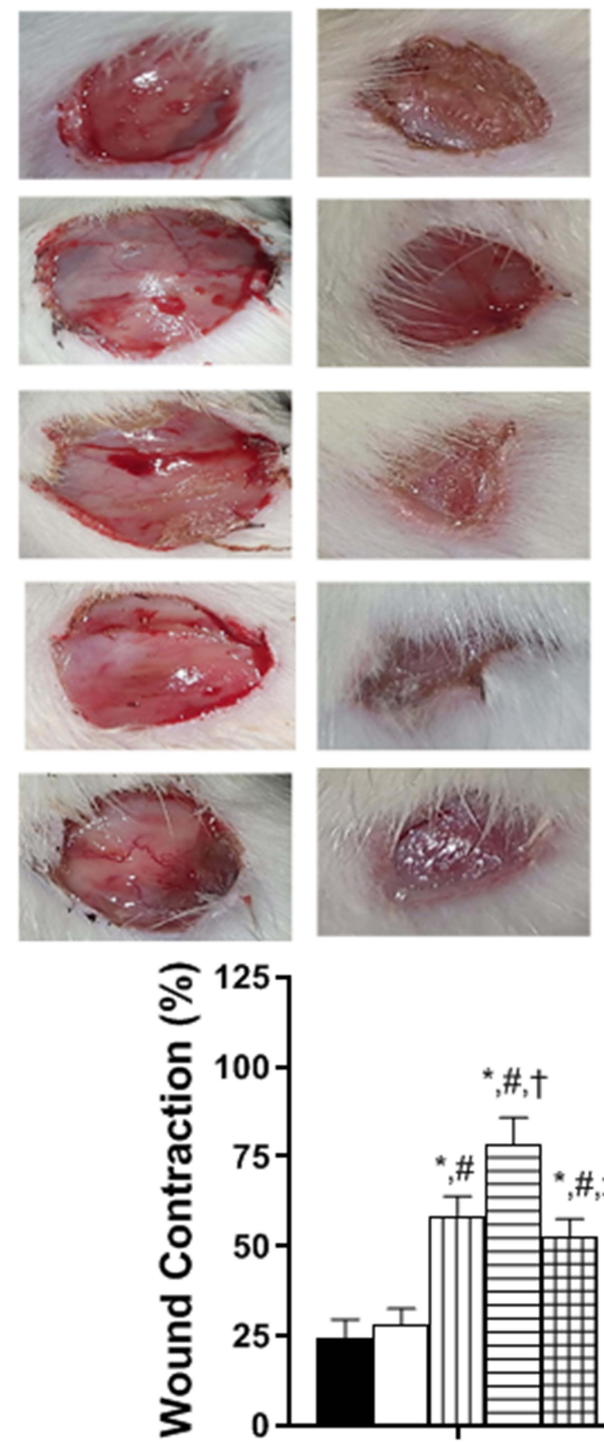

Day 3
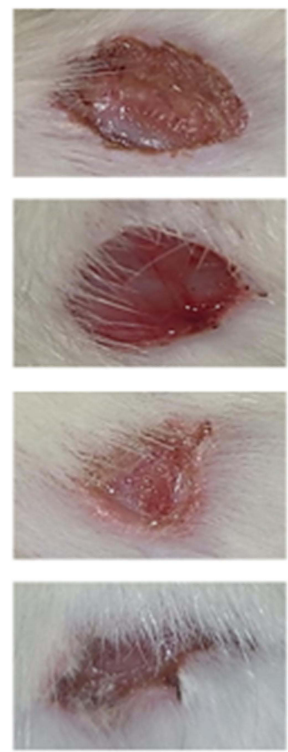

\section{B}

Day 7
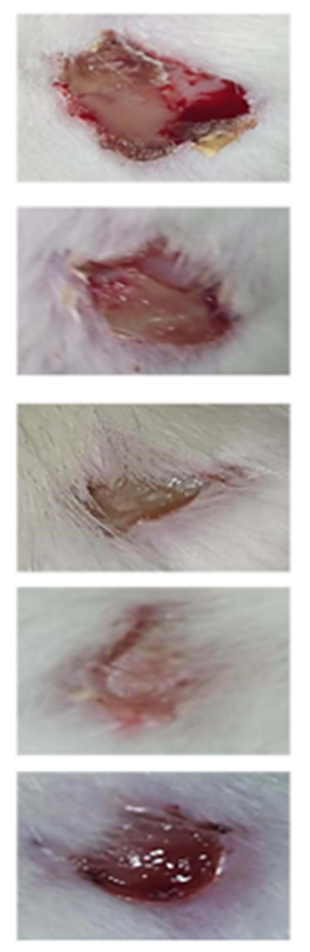

Day 10
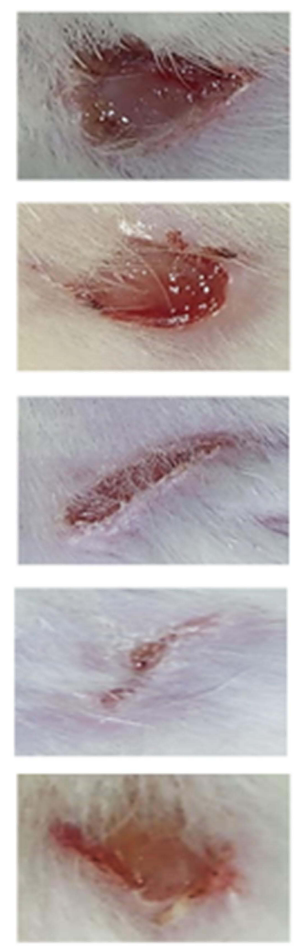

\section{Day 14}
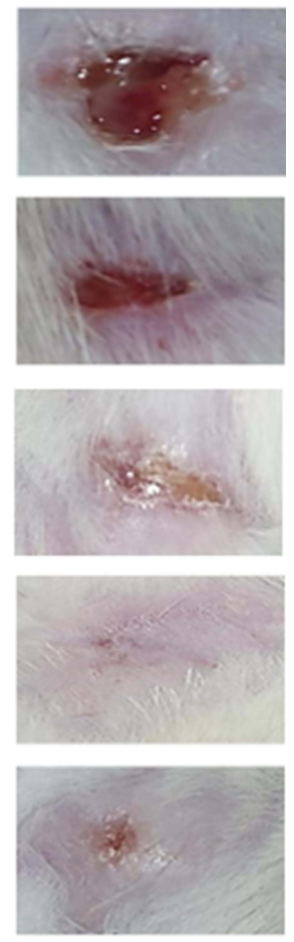

- Untreated Control

$\square$ Vehicle-Treated Control

m $\mathrm{OI}$ OFI

$\sqsupseteq$ OFI-SNEDDS

뚀 Positive Control

Figure 4 (A) Photographs showing wound closure in rats treated with topical application of OFI-SNEDDS on day 7 and day I4. (B) Effects of different treatments on percent wound closure. Data are presented as Mean \pm SD $(n=6)$. Statistical analysis was performed by one-way ANOVA followed by Tukey's test. *Significant difference from Untreated Control group at $p<0.05$. ${ }^{\#}$ Significant difference from vehicle-treated group at $p<0.05$. ${ }^{\dagger}$ Significant difference from OFI group at $p<0.05$. ${ }^{\ddagger}$ Significant difference from OFI-SNEDDS group at $p<0.05$. 


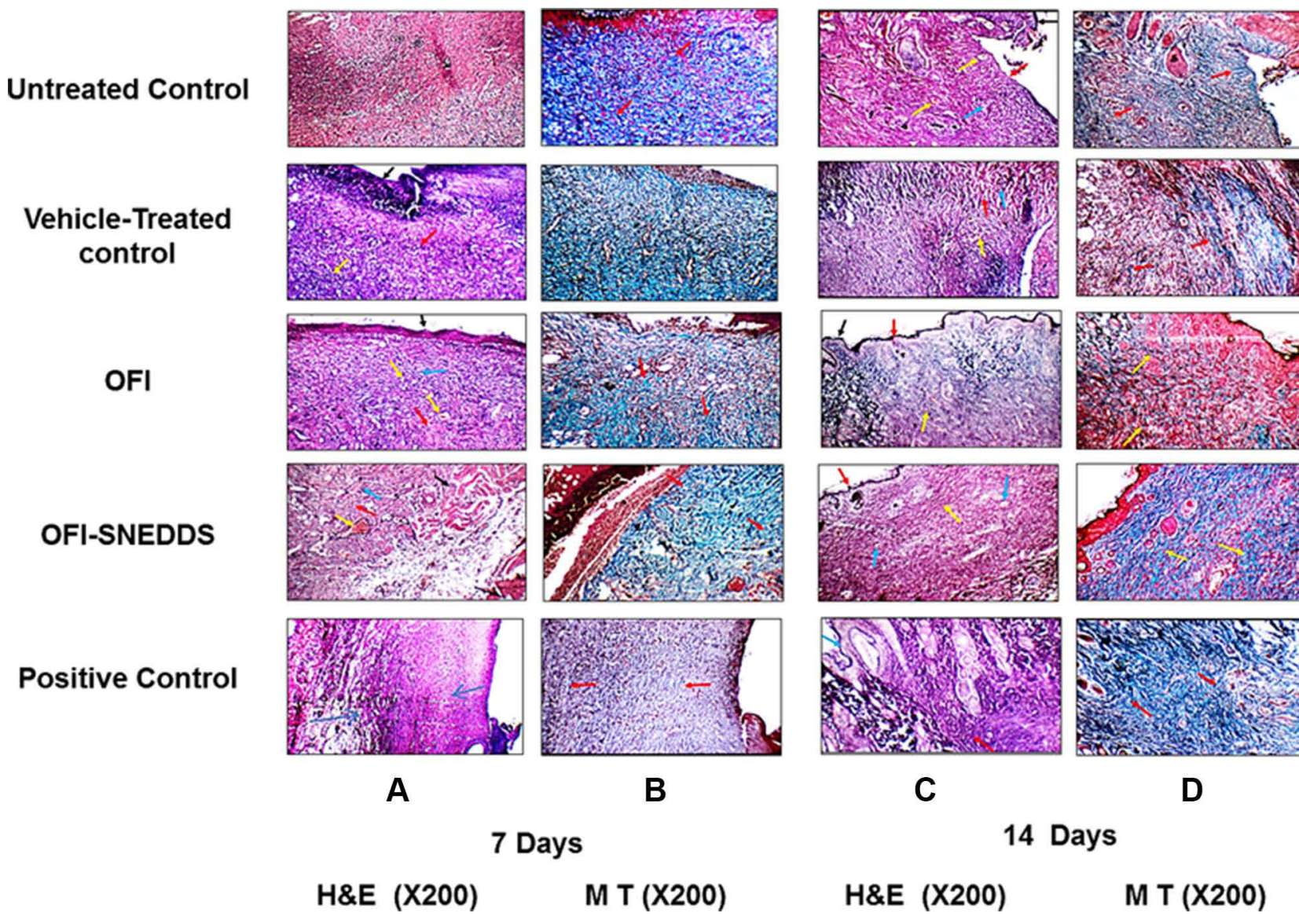

Figure 5 Histopathology effect of OFI and OFI-SNEDDS on wound healing of rats (X200). Panels A \& B represent skin sections from wound areas collected at day 7 and stained with H\&E and MT, respectively. Panels C \& D represent skin sections from wound areas collected at day 14 and stained with H\&E and MT, respectively. Arrows indicate healthy skin (black arrows), collagen deposition (red arrows), inflammatory infiltration (blue arrows), Congestion (yellow arrows).

rats showed moderate collagen deposition (CD), no inflammatory cells infiltration (IC) and mostly Phase III (re-modeling) of wound healing (Table 4).

\section{Effect of OFI-SNEDDS on Oxidative Status on Day 14}

The data in Table 5 indicate that wound tissues treated with OFI-SNEDDS and the positive control significantly lowered MDA content by 40 and $35 \%$ as compared to Vehicle-treated control, respectively. In addition, OFI-SNEDDS showed the highest antioxidant activity as compared OFI and the positive group animals. It significantly enhanced GSH, SOD and GPx in wound tissues by 33,65 and $42 \%$ as compared to Vehicletreated control, respectively.

\section{Effect of OFI-SNEDDS on Inflammation on Day 14}

Figure 6A indicates that OFI and OFI-SNEDDS significantly lowered IL- 6 in wound tissues by 32 and $49 \%$ of the untreated control value, respectively. Similarly, wound

Table 4 Histological Features of Wound Healing in Animals Treated Topically with OFI-SNEDDS on Day 7

\begin{tabular}{|l|c|c|c|c|c|c|c|}
\hline & RE & GT & CD & IC & Inflammation Phase & Proliferation Phase & Remodeling Phase \\
\hline Untreated Control & - & + & + & ++ & ++ & ++ & - \\
Vehicle-treated & - & ++ & + & ++ & ++ & ++ & - \\
OFI & + & +++ & + & \pm & + & +++ & ++ \\
OFI-SNEDDS & + & + & ++ & - & + & ++ & ++ \\
Positive Control & + & ++ & ++ & \pm & ++ & +++ & ++ \\
\hline
\end{tabular}

Notes: $(-)$ Absence of the histological feature, $(+)$ Low-degree, $(++)$ Intermediate-degree, $(+++)$ High-degree, $( \pm)$ Absence or Low-degree feature.

Abbreviations: RE, Re-epithelization; GT, Granulation tissue; CD, Collagen deposition; IC, Inflammatory cell infiltration. 
Table 5 Effect of OFI-SNEDDS on Oxidative Stress in Wounded Skin of Rats

\begin{tabular}{|l|l|l|l|l|}
\hline & $\begin{array}{l}\text { MDA (nmol/mg } \\
\text { Protein) }\end{array}$ & $\begin{array}{l}\text { GSH (nmol/mg } \\
\text { Protein) }\end{array}$ & $\begin{array}{l}\text { SOD (Unit/mg } \\
\text { Protein) }\end{array}$ & $\begin{array}{l}\text { GPx (nmol/mg } \\
\text { Protein) }\end{array}$ \\
\hline Untreated Control & $7.60 \pm 0.88$ & $1.55 \pm 0.18$ & $6.43 \pm 0.31$ & $2.93 \pm 0.47$ \\
Vehicle-treated Control & $7.20 \pm 0.82$ & $1.70 \pm 0.19$ & $6.46 \pm 0.57$ & $3.31 \pm 0.47$ \\
OFI & $5.30 * \# 0.62$ & $2.10 * \pm 0.26$ & $7.80 * \pm 0.81$ & $3.79 * \pm 0.39$ \\
OFI-SNEDDS & 4.3 * $^{*} \pm 0.42$ & $2.60 * \# \pm 0.23$ & $8.73 * \# \pm 0.88$ & $4.06 * \pm 0.31$ \\
Positive Control & $5.11 *^{* \#} \pm 0.57$ & $2.30 * \pm 0.30$ & $7.79 * \# \pm 0.88$ & $3.90 * \pm 0.46$ \\
\hline
\end{tabular}

Notes: Data are presented as Mean \pm SD $(n=6)$. Statistical analysis was performed by one-way ANOVA followed by Tukey's test. *Significant difference from Untreated Control group at $p<0.05$. "Significant difference from vehicle-treated control at $p<0.05$. 'Significant difference from OFI group at $p<0.05$.

tissue content of TNF- $\alpha$ was significantly decreased by both preparations by 48 and $60 \%$ of the untreated control animals, respectively (Figure 6B).

\section{Effect of OFI-SNEDDS on Collagen Formation on Day 14}

Figure 7A illustrates that both OFI and OFI-SNEDDS significantly enhanced hydroxyproline skin content by 57 and $73 \%$ of the vehicle-treated control, respectively. Also, both preparations upregulated CollA1 mRNA relative expression by approximately 20 and $87 \%$ of the Vehicletreated control, respectively (Figure 7B).

\section{Effect of OFI-SNEDDS on TGF- $\beta$ and VEGF Expressions on Day 14}

Expression of TGF- $\beta$ and VEGF - as fibrotic and angiogenic markers, respectively - was utilized to assess the degree of wound healing. Figure $8 \mathrm{~A}$ and $\mathrm{B}$ reflect the degree of TGF- $\beta$ expression in wounds of untreated and vehicle-treated controls. Treatment with OFI oil (Figure 8C) caused a significant increase of TGF- $\beta$ expression, compared to untreated and vehicle-treated controls.
Furthermore, treatment with OFI-SNEDDS and positive control (Figure 8D and E) markedly improved TGF- $\beta$ expression by about three folds compared to untreated and vehicle-treated groups, being quantified as OD in Figure 8F.

A similar pattern of activity was detected for VEGF expression as shown in Figure 9. However, OFI oil (Figure 9C) failed to improve this angiogenic marker over untreated and vehicle-treated controls. Only OFISNEDDS and positive control groups (Figure 9D and E) showed a marked increase in VEGF expression as intense brown staining compared to untreated and vehicle-treated controls. This effect was confirmed by quantitation of VEGF expression as OD as shown in Figure 9F.

\section{Characterization of the Oil}

A detailed characterization of the oil was previously published by the same authors (Supplementary Table 1) ${ }^{17}$ Palmitic acid (10.68\%), linoleic acid (5.9\%), oleic acid $(8.16 \%)$, campesterol $(6.58 \%)$ and $\beta$-sitosterol $(24.98 \%)$ are the major constituents in OFI seed oil (Figure 10).
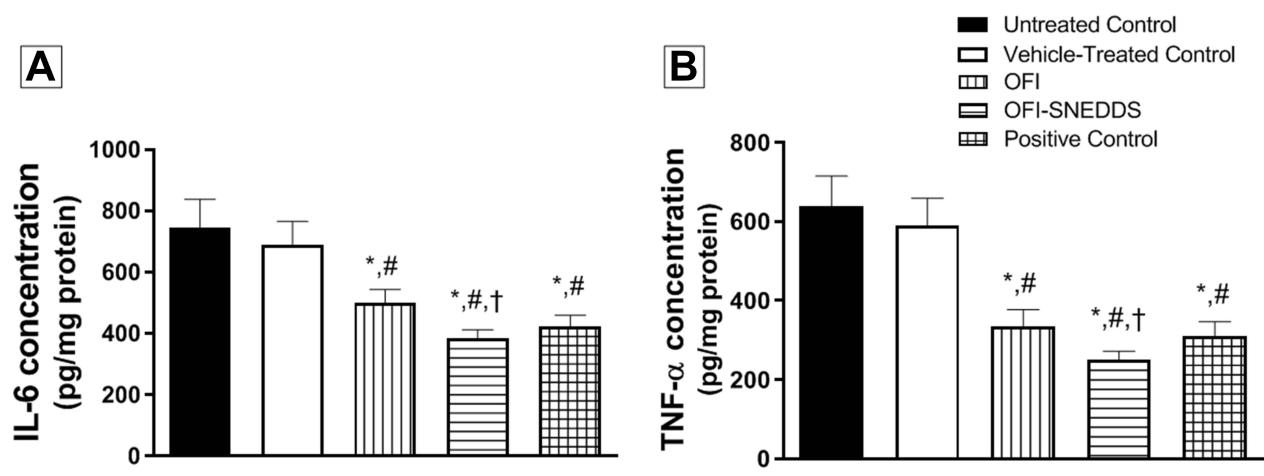

Figure 6 Effect of OFI-SNEDDS on inflammation in wounded skin of rats. (A) represents IL- 6 content and (B) represents TNF- $\alpha$ content. Data are presented as Mean \pm SD $(n=6)$. Statistical analysis was performed by one-way ANOVA followed by Tukey's test. *Significant difference from Untreated Control group at $p<0.05$. ${ }^{\#}$ Significant difference from vehicle-treated group at $p<0.05$. `Significant difference from OFI group at $p<0.05$. 


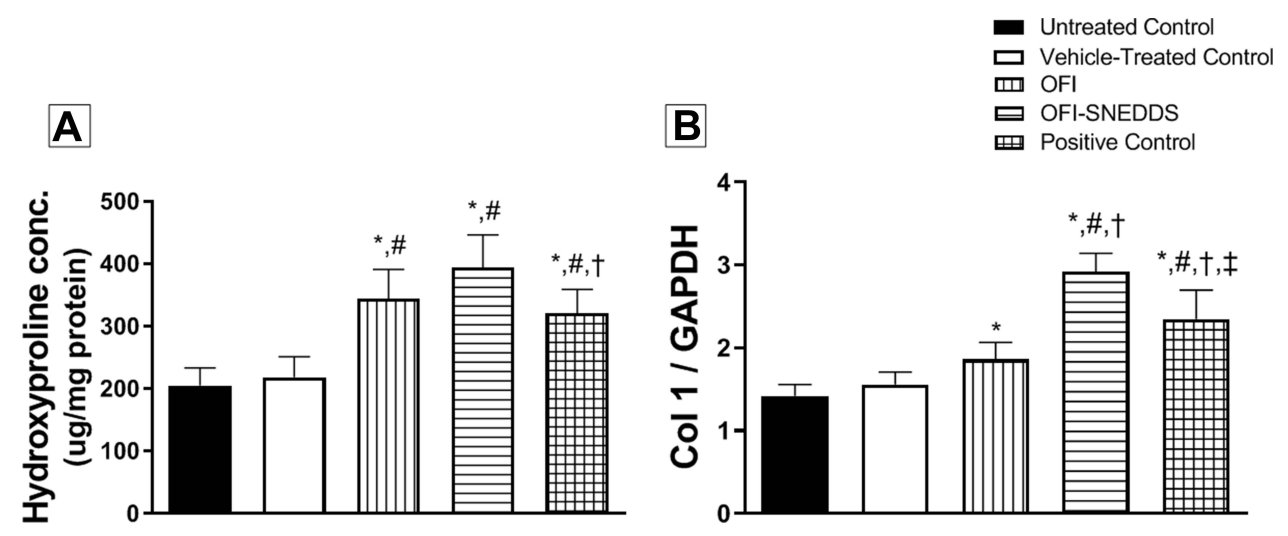

Figure 7 Effect of OFI-SNEDDS on collagen formation in wounded skin of rats. (A) represents hydroxyproline content and (B) represents Col I relative mRNA expression. Data are presented as Mean \pm SD $(n=6)$. Statistical analysis was performed by one-way ANOVA followed by Tukey's test. *Significant difference from Untreated Control group at $\mathrm{p}<0.05$. ${ }^{\#}$ Significant difference from vehicle-treated group at $\mathrm{p}<0.05$. ${ }^{\dagger}$ Significant difference from OFI group at $\mathrm{p}<0.05$. ${ }^{\ddagger}$ Significant difference from OFI-SNEDDS group at $\mathrm{p}<0.05$.

\section{Discussion}

Surgical and diabetic wounds represent a worldwide health hazard, being the most difficult to heal among chronic wounds. Decades ago, traditional herbal products have been often utilized for wound healing purposes. It has been reported that OFI seed oil from Tunisia was efficient in wound healing. ${ }^{16}$ Nevertheless, Saudi OFI seed oil was not investigated for its potential for wound healing. In the current work, SNEDDS was used to improve the delivery and wound healing properties of OFI seed oil, in a fullthickness skin excisional model in rats in order to investigate SNEDDS of the OFI oil and the oil itself for their wound healing activity.

Self-emulsifying formulations were found to spread readily. Such formulation approaches not only have the advantage of presenting the drug in a highly solubilized form, but also are characterized by a small average droplet size that offers a large interfacial area for enhanced absorption of the loaded therapeutics. Unlike regular emulsions, which typically produce turbid-to-opaque formulations, SNEDDSs produce translucent nano-emulsions. Compared with traditional emulsions that are sensitive dispersed forms of low stability characteristics, SNEDDSs are found to be a promising approach, as they are thermodynamically stable and easy-to-produce formulations. Thus, for drugs of a lipophilic nature with dissolving-dependent absorption, such systems may greatly enhance the rate and extent of penetration via skin layers, leading to more reproducible skin concentration-time profiles. Nano-sized emulsions are composed chiefly of isotopic mixtures of oil, surface active agent and cosurfactant, which undergo spontaneous process of in-situ emulsions formation under gentle agitation upon contact with skin fluids, therefore favoring rapid formation of fine emulsion, ie, in-situ emulsions. ${ }^{18,34,35}$

The current findings showed that both OFI-SNEDDS and free OFI oil improved the wound healing process, compared to wounds covered with the standard Mebo ${ }^{\circledR}$ ointment, vehicle, and untreated groups. However, tissue reconstruction and healing time improved significantly in the OFI-SNEDDS group, relative to the OFI oil group. OFI-SNEDDS accelerated the rate of wound closure; for instance, at day 3 post-wounding, a slight decrease in swelling in animals treated with OFI-SNEDDS was detected. This effect was comparable to that of OFI oiltreated animals and higher than those of Mebo ${ }^{\circledR}$, vehicle and the untreated groups. At days 7 and 14, a significantly enhanced wound healing effect of OFI-SNEDDS was observed compared to OFI seed oil, which may be attributed initially to the enhancement in tissue uptake of OFI oil from SNEDDS. In addition, these results may reflect the effect of OFI-SNEDDS on the early phases of the healing process, thus affecting the whole epithelization period, which was significantly shorter, relative to the OFI oil group and the standard group. This reduction in healing time and enhanced wound contraction by OFISNEDDS were enabled by nanosized droplets of SNEDDS, which have been investigated for their enhancement of the therapeutic effect of several essential oils with potential wound healing properties. ${ }^{36,37}$ Hence, SNEDDS of OFI seed oil was chosen in this study for OFI's enhancement of wound healing efficacy.

Histopathological examinations of OFI-SNEDDS-treated animals at days 7 and 14 showed signs of healed skin 

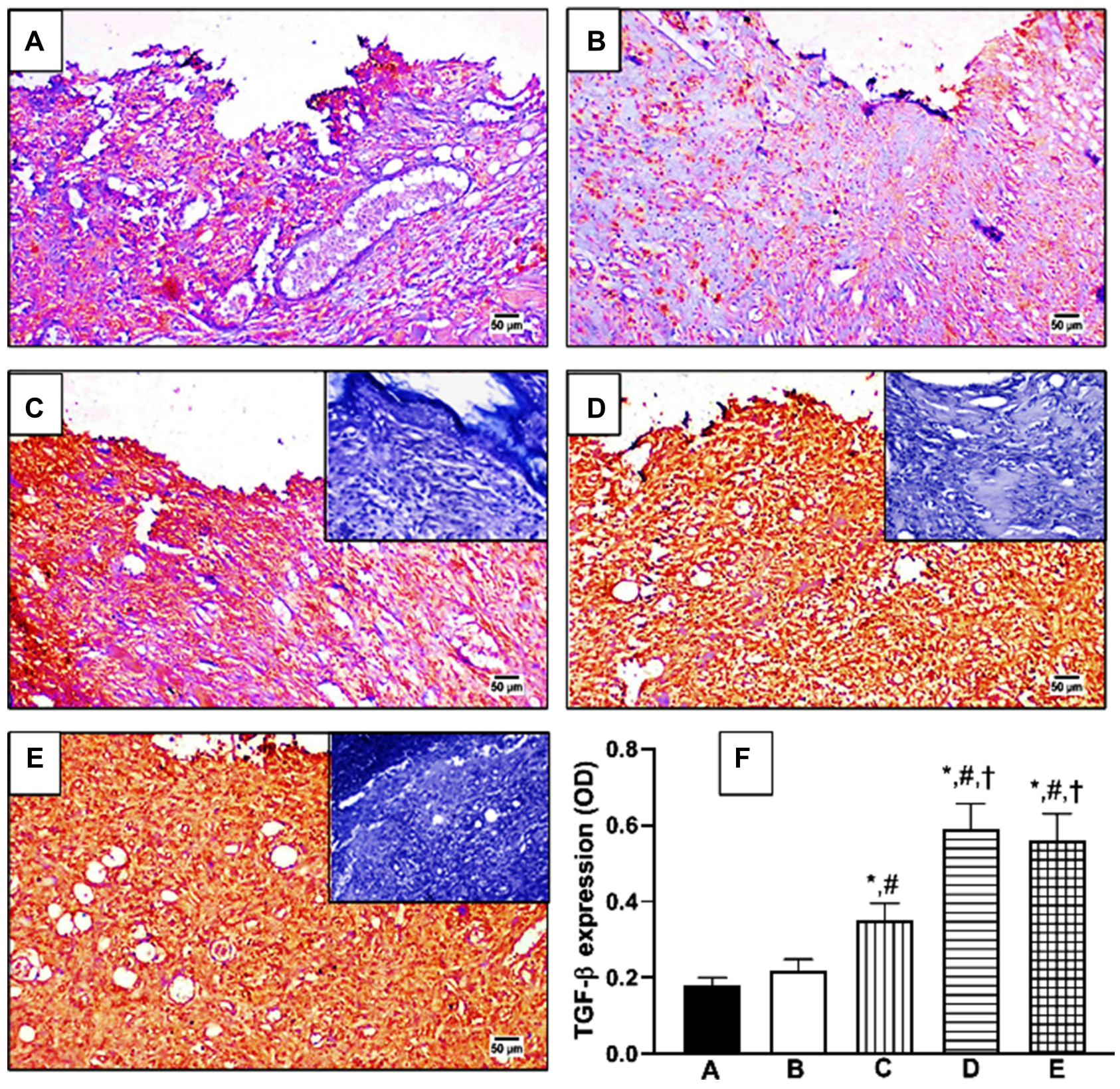

Figure 8 Effect of OFI-SNEDDS on expression of transforming growth factor-beta (TGF- $\beta$ ) by immunohistochemical staining. (A) Untreated Control; (B) Vehicle-treated Control; (C) OFI; (D) OFI-SNEDDS; (E) Positive Control. Negative photographs are put as inserts in their respective ones with strong positive reaction (C, D and E). (F) Quantitative image analysis for TGF- $\beta$ immuno-histochemical staining, expressed as optical density (OD). Data are presented as Mean \pm SD ( $n=6$ ). Statistical analysis was performed by one-way ANOVA followed by Tukey's test. *Significant difference from Untreated Control group at $p<0.05$. "Significant difference from vehicle-treated group at $p<0.05$. 'Significant difference from OFI group at $p<0.05$

structure, characterized by elimination of ulceration and epithelization, as well as extensive formation of fibrosis and collagen tissue. Furthermore, there was a significant reduction in the accumulation of inflammatory cells, indicating the safety of SNEDDS in rats. It has been reported that restoration of injured tissue proceeds in several steps, including inflammation, wound contraction, angiogenesis, and extracellular matrix deposition. ${ }^{36,38}$ Single or several mechanisms may occur in each phase, which results in the overall outcome of the wound healing process. Regeneration of a wounded tissue starts by the recruitment of immune cells, such as neutrophils and macrophages, to the injured area to secrete inflammatory mediators, such as TNF- $\alpha$, and IL- 6 , as well as various chemotactic cytokines and growth factors, to attract more inflammatory cells, and to promote the proliferation of fibroblasts. The regulation of this early stage of inflammatory response is a key factor in the wound repair effect of OPI-SNEDDS, as it inhibits 

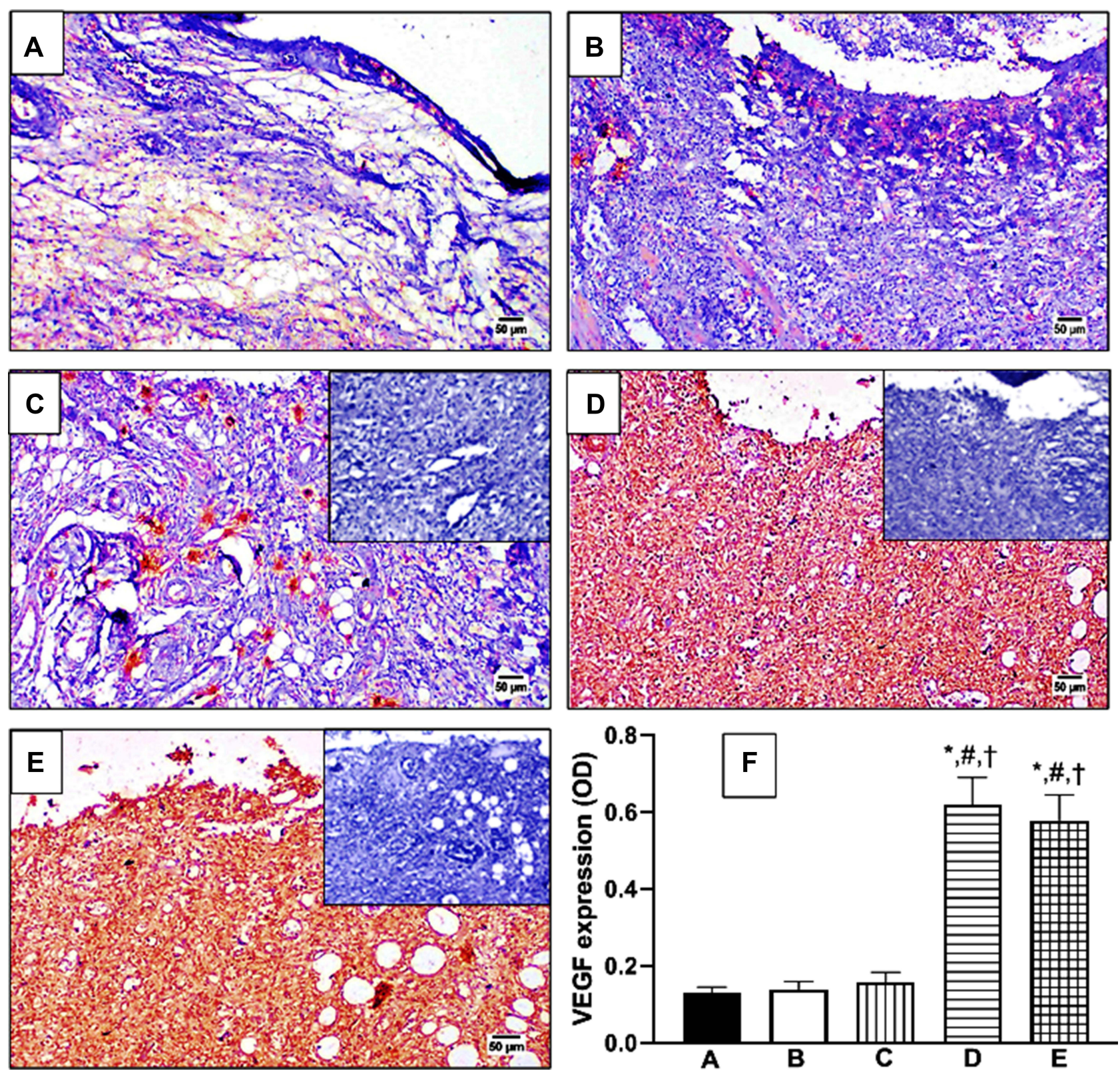

Figure 9 Effect of OFI-SNEDDS on expression of vascular endothelial growth factor (VEGF) by immunohistochemical staining. (A) Untreated Control; (B) Vehicle-treated Control; (C) OFI; (D) OFI-SNEDDS; (E) Positive Control. Negative photographs are put as inserts in their respective ones with strong positive reaction (C, D and E). (F) Quantitative image analysis for TGF- $\beta$ immuno-histochemical staining, expressed as optical density (OD). Data are presented as Mean \pm SD $(n=6)$. Statistical analysis performed by one-way ANOVA followed by Tukey's test. *Significant difference from Untreated Control group at $p<0.05$. " Significant difference from vehicle-treated group at $p<0.05$. 'Significant difference from OFl group at $p<0.05$.

the accumulation of inflammatory cells with respect to the OFI group and significantly decreases the expression of inflammatory cytokines IL- 6 and TNF- $\alpha$ rats' tissues. Collagen disposition can occur during the first stage and continue throughout the healing process. OPI-SNEDDS showed enhanced collagen content stained with Masson's trichrome and high expression in Col1A1 gene and hydroxyproline, the major component of collagen and indicator of the amount of collagen compared to OFI. The three parameters were lower in the case of OPI treatment, which explains the prolonged inflammatory phase. Overall, SNEDDS was advantageous in terms of collagen content, which helped in wound healing effects because it provides strength to repair tissues. ${ }^{39,40}$

Wound healing activity could be attributed to the different constituents of OFI oil. The oil is rich in a mixture of fatty acids (saturated and unsaturated) that are essential for the repair of mammalian cellular tissues. Fatty acids 


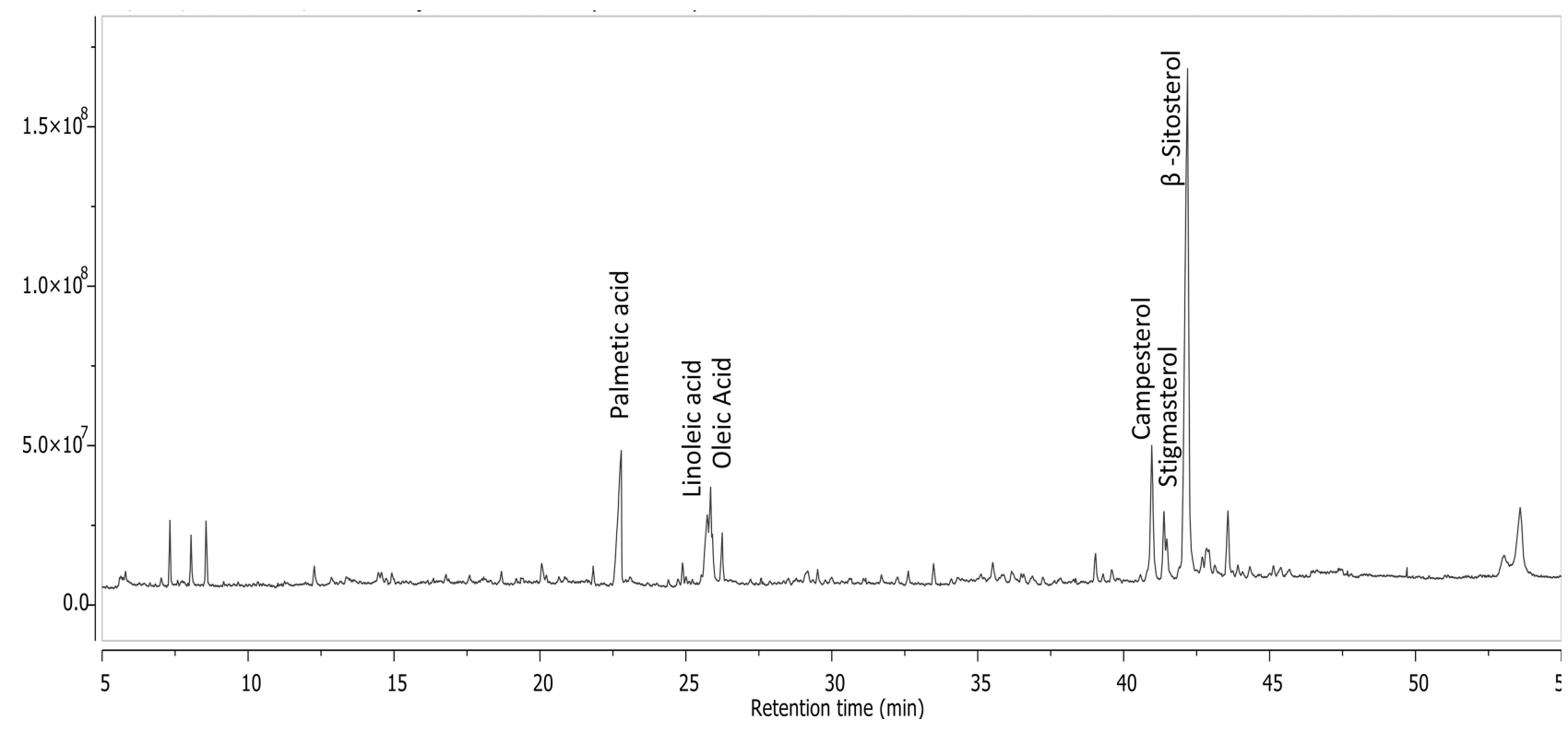

Figure 10 Total ion chromatogram of GC/MS analysis of hexane fraction of OFI seeds.

alter the maturation and differentiation of the stratum corneum, the outer layer of the skin, thus affecting skin's structural and immunological status and enhancing permeability. In addition, fatty acids inhibit production of reactive oxygen and nitrogen species as well as cytokines, hence influencing the inflammatory response and wound healing. ${ }^{41}$ ROS are overproduced and hence, lipid peroxidation occurs at the wound site as a defensive mechanism which causes oxidative stress and cytotoxicity, which delays wound healing. ${ }^{42}$ Consequently, antioxidant activation may improve wound healing by decreasing free radicals and ROS elimination, which would be a successful target in wound healing. ${ }^{43}$ Herein, clear decrease in MDA tissue concentration in the OFI-SNEDDS group suggests that the enhanced healing activity occurs through the inhibition of lipid peroxidation. In addition, OFI-SNEDDS showed the highest antioxidant activity with regard to GSH, SOD and GPx, compared to OFI seed oil. This also suggests that OFI-SNEDDS accelerates wound healing by the remarkable enhancement in antioxidant enzyme activities.

Linoleic acid ( $\omega-6)$ (LA), which is one of the major constituents of OFI seed oil, was reported to improve wound healing due to its ability to maintain hydration and its biphasic effects on the inflammatory phase of tissue repair. ${ }^{41}$ Moreover, linoleic acid was responsible for the wound healing activity of pumpkin and lucuma nut oils. ${ }^{41}$ Its effect may also relate to its ability to increase production of nitric oxide (NO), which plays important roles in the activation of macrophages and fibroblasts, as well as extracellular matrix disposition, thus accelerating reepithelization. Oleic acid ( $\omega-9)$ is another major constituent of OFI oil $(8.16 \%)$, and it produces differential wound repair activity due to its ability to modulate both inflammatory and immune responses in skin injuries. This could therefore be used in the treatment of cutaneous wounds, particularly in skin burns, and diabetic or pressure ulcers.44 It raises the number of neutrophils in the wound and reduces the thickness of necrotic tissue. Moreover, it increases the release of vascular endothelial growth factor-alpha (VEGF- $\alpha$ ) and interleukin-1beta (IL-1 $\beta$ ) after incubation of neutrophils. $^{45}$ In fact, OFI oil contains $(24.98 \%)$ of $\beta$-sitosterol that is considered as an angiogenic factor, which stimulated neovascularization in the mouse matrigel plug assay and the motility of human umbilical vein endothelial cells in an in-vitro wound migration assay. ${ }^{46,47}$ Based on the current findings, it could be concluded that OFI seed oil possesses wound healing properties that is enhanced by self-emulsification of the oil into nano-droplets. The observed activity can be attributed, at least partly, to its anti-inflammatory, procollagen and angiogenic properties.

\section{Conclusion}

In the current study, optimized OFI-SNEDDS formula exhibited a superior wound healing activity to regular OFI seed oil, in excision wound model in rats. This 
could be attributed, at least partly, to its antioxidant, antiinflammatory, pro-collagen and angiogenic properties.

\section{Acknowledgments}

This project was funded by the Deanship of Scientific Research (DSR) at King Abdulaziz University, Jeddah, under grant no (RG-14-166-40). The authors, therefore, acknowledge with thanks DSR's technical and financial support.

\section{Disclosure}

The authors report no conflicts of interest in this work.

\section{References}

1. Cañedo-Dorantes L, Cañedo-Ayala M. Skin acute wound healing: a comprehensive review. Int J Inflam. 2019;2019:1-15. doi:10.1155/ 2019/3706315

2. Rodrigues M, Kosaric N, Bonham CA, Gurtner GC. Wound healing: a cellular perspective. Physiol Rev. 2019;99(1):665-706. doi:10.1152/ physrev.00067.2017

3. Sen CK. Human Wounds and Its Burden: An Updated Compendium of Estimates. 140 Huguenot Street: Mary Ann Liebert, Inc., Publishers; 2019:39-48.

4. Martinengo L, Olsson M, Bajpai R, et al. Prevalence of chronic wounds in the general population: systematic review and meta-analysis of observational studies. Ann Epidemiol. 2019;29:8-15. doi:10.1016/j.annepidem.2018.10.005

5. Lazarus GS, Cooper DM, Knighton DR, et al. Definitions and guidelines for assessment of wounds and evaluation of healing. Wound Repair Regen. 1994;2(3):165-170. doi:10.1046/j.1524475X.1994.20305.x

6. Thakur R, Jain N, Pathak R, Sandhu SS. Practices in wound healing studies of plants. Evid Based Complement Alternat Med. 2011;2011:1-17. doi:10.1155/2011/438056

7. Wallace HA, Basehore BM, Zito PM. Wound Healing Phases. 2019.

8. Slemp AE, Kirschner RE. Keloids and scars: a review of keloids and scars, their pathogenesis, risk factors, and management. Curr Opin Pediatr. 2006;18(4):396-402. doi:10.1097/01. mop.0000236389.41462.ef

9. Pereira RF, Bartolo PJ. Traditional therapies for skin wound healing. Adv Wound Care. 2016;5(5):208-229. doi:10.1089/wound.2013.0506

10. Maver T, Maver U, Stana Kleinschek K, Smrke DM, Kreft S. A review of herbal medicines in wound healing. Int $J$ Dermatol. 2015;54(7):740-751. doi:10.1111/ijd.12766

11. Dorai AA. Wound care with traditional, complementary and alternative medicine. Indian J Plast Surg. 2012;45(2):418. doi:10.4103/ 0970-0358.101331

12. Rex J, Muthukumar N, Selvakumar P. Phytochemicals as a potential source for antimicrobial, anti-oxidant and wound healing-a review. MOJ Biorg Org Chem. 2018;2(2):61-70.

13. Varijakzhan D, Chong C-M, Abushelaibi A, Lai K-S, Lim S-HE. Middle eastern plant extracts: an alternative to modern medicine problems. Molecules. 2020;25(5):1126. doi:10.3390/ molecules25051126

14. Galati EM, Mondello MR, Monforte MT, Galluzzo M, Miceli N, Tripodo MM. Effect of Opuntia ficus-indica (L.) Mill. cladodes in the wound-healing process. J Prof Assoc Cactus Dev. 2003;5:1-16.

15. Park E-H, Chun M-J. Wound healing activity of Opuntia ficus-indica. Fitoterapia. 2001;72(2):165-167. doi:10.1016/S0367-326X(00) 00265-3
16. Khémiri I, Essghaier Hédi B, Sadfi Zouaoui N, Ben Gdara N, Bitri L. The antimicrobial and wound healing potential of Opuntia ficus indica 1. inermis extracted oil from tunisia. Evid Based Complement Alternat Med. 2019;2019:2019. doi:10.1155/2019/9148782

17. Koshak AE, Abdallah HM, Esmat A, Rateb ME. Anti-inflammatory activity and chemical characterisation of Opuntia ficus-indica seed oil cultivated in Saudi Arabia. Arab J Sci Eng. 2020;1-8.

18. Altamimi MA, Kazi M, Hadi Albgomi M, Ahad A, Raish M. Development and optimization of self-nanoemulsifying drug delivery systems (SNEDDS) for curcumin transdermal delivery: an antiinflammatory exposure. Drug Dev Ind Pharm. 2019;45(7):10731078. doi:10.1080/03639045.2019.1593440

19. Ahmed OA, Badr-Eldin SM. In situ misemgel as a multifunctional dual-absorption platform for nasal delivery of raloxifene hydrochloride: formulation, characterization, and in vivo performance. Int $J$ Nanomedicine. 2018;13:6325. doi:10.2147/IJN.S181587

20. Alhakamy NA, Fahmy UA, Ahmed OA, et al. Development of an optimized febuxostat self-nanoemulsified loaded transdermal film: invitro, ex-vivo and in-vivo evaluation. Pharm Dev Technol. 2020;25 (3):326-331. doi:10.1080/10837450.2019.1700520

21. Basalious EB, Shawky N, Badr-Eldin SM. SNEDDS containing bioenhancers for improvement of dissolution and oral absorption of lacidipine. I: development and optimization. Int J Pharm. 2010;391 (1-2):203-211. doi:10.1016/j.ijpharm.2010.03.008

22. Aldawsari HM, Elfaky MA, Fahmy UA, Aljaeid BM, Alshareef OA, Khalid M. Development of a fluvastatin-loaded self-nanoemulsifying system to maximize therapeutic efficacy in human colorectal carcinoma cells. J Drug Deliv Sci Technol. 2018;46:7-13. doi:10.1016/j. jddst.2018.04.015

23. Fahmy UA. Nanoethosomal transdermal delivery of vardenafil for treatment of erectile dysfunction: optimization, characterization, and in vivo evaluation. Drug Des Devel Ther. 2015;9:6129. doi:10.2147/ DDDT.S94615

24. Chbani M, Matthäus B, Charrouf Z, et al. Characterization of phenolic compounds extracted from cold pressed cactus (Opuntia ficusindica L.) seed oil and the effect of roasting on their composition. Foods. 2020;9(8):1098. doi:10.3390/foods9081098

25. Buchwalow IB, Böcker W. Immunohistochemistry. Basics Methods. 2010;1:1-149.

26. Singh B, Bhatowa R, Tripathi CB, Kapil R. Developing micro-/ nanoparticulate drug delivery systems using "design of experiments". Int J Pharm Investig. 2011;1(2):75. doi:10.4103/2230-973X.82395

27. Ahmed OA, El-Say KM, Aljaeid BM, Badr-Eldin SM, Ahmed TA. Optimized vinpocetine-loaded vitamin E D- $\alpha$-tocopherol polyethylene glycol 1000 succinate-alpha lipoic acid micelles as a potential transdermal drug delivery system: in vitro and ex vivo studies. Int J Nanomedicine. 2019;14:33. doi:10.2147/IJN.S187470

28. Fahmy UA, Badr-Eldin SM, Ahmed OA, et al. Intranasal niosomal in situ gel as a promising approach for enhancing flibanserin bioavailability and brain delivery: in vitro optimization and ex vivo/in vivo evaluation. Pharmaceutics. 2020;12(6):485. doi:10.3390/ pharmaceutics 12060485

29. Sakeena MHF, Munavvar AS. Effects of oil and drug concentrations on droplets size of palm oil esters (POEs) nanoemulsion. J Oleo Sci. 2011;60(4):155-158. doi:10.5650/jos.60.155

30. Balata GF, Essa EA, Shamardl HA, Zaidan SH, Abourehab MA. Selfemulsifying drug delivery systems as a tool to improve solubility and bioavailability of resveratrol. Drug Des Devel Ther. 2016;10:117. doi:10.2147/DDDT.S95905

31. Gao W, Jiang Z, Du X, et al. Impact of surfactants on nanoemulsions based on fractionated coconut oil: emulsification stability and in vitro digestion. J Oleo Sci. 2020;69(3):ess19264. doi:10.5650/jos.ess19264

32. Ghosh V, Saranya S, Mukherjee A, Chandrasekaran N. Cinnamon oil nanoemulsion formulation by ultrasonic emulsification: investigation of its bactericidal activity. J Nanosci Nanotechnol. 2013;13(1):114122. doi:10.1166/jnn.2013.6701 
33. Zhang L, Zhang L, Zhang M, et al. Self-emulsifying drug delivery system and the applications in herbal drugs. Drug Deliv. 2015;22 (4):475-486. doi:10.3109/10717544.2013.861659

34. Badran MM, Taha EI, Tayel MM, Al-Suwayeh SA. Ultra-fine self nanoemulsifying drug delivery system for transdermal delivery of meloxicam: dependency on the type of surfactants. J Mol Liq. 2014;190:16-22. doi:10.1016/j.molliq.2013.10.015

35. Rehman FU, Shah KU, Shah SU, Khan IU, Khan GM, Khan A. From nanoemulsions to self-nanoemulsions, with recent advances in selfnanoemulsifying drug delivery systems (SNEDDS). Expert Opin Drug Deliv. 2017;14(11):1325-1340. doi:10.1080/ 17425247.2016.1218462

36. Shakeel F, Alam P, Anwer MK, Alanazi SA, Alsarra IA, Alqarni MH Wound healing evaluation of self-nanoemulsifying drug delivery system containing Piper cubeba essential oil. 3 Biotech. 2019;9 (3):1-9. doi:10.1007/s13205-019-1630-y

37. Alam P, Ansari MJ, Anwer MK, Raish M, Kamal YK, Shakeel F. Wound healing effects of nanoemulsion containing clove essential oil. Artif Cells Nanomed Biotechnol. 2017;45(3):591-597. doi:10.3109/21691401.2016.1163716

38. Velnar T, Bailey T, Smrkolj V. The wound healing process: an overview of the cellular and molecular mechanisms. J Int Med Res. 2009;37(5):1528-1542. doi:10.1177/147323000903700531

39. Sawatdee S, Choochuay K, Chanthorn W, Srichana T. Evaluation of the topical spray containing Centella asiatica extract and its efficacy on excision wounds in rats. Acta Pharm. 2016;66(2):233-244. doi:10.1515/acph-2016-0018
40. Süntar I, Küpeli Akkol E, Tosun A, Keleş H. Comparative pharmacological and phytochemical investigation on the wound-healing effects of the frequently used essential oils. $J$ Essent Oil Res. 2014;26(1):41-49. doi:10.1080/10412905.2013.820672

41. Silva JR, Burger B, Kühl C, Candreva T, Dos Anjos MB, Rodrigues HG. Wound healing and omega- 6 fatty acids: from inflammation to repair. Mediators Inflamm. 2018;2018:1-17. doi:10.1155/2018/ 2503950

42. Rasik AM, Shukla A. Antioxidant status in delayed healing type of wounds. Int J Exp Pathol. 2000;81(4):257-263. doi:10.1046/j.13652613.2000.00158.x

43. Mikhal'chik E, Anurov M, Titkova S, et al. Activity of antioxidant enzymes in the skin during surgical wounds. Bull Exp Biol Med. 2006;142(6):667-669. doi:10.1007/s10517-006-0446-Z

44. Cardoso C, Favoreto JS Jr, Oliveira L, et al. Oleic acid modulation of the immune response in wound healing: a new approach for skin repair. Immunobiology. 2011;216(3):409-415. doi:10.1016/j. imbio.2010.06.007

45. Bonferoni M, Sandri G, Dellera E, et al. Ionic polymeric micelles based on chitosan and fatty acids and intended for wound healing. Comparison of linoleic and oleic acid. Eur J Pharm Biopharm. 2014;87(1):101-106. doi:10.1016/j.ejpb.2013.12.018

46. Tsala DE, Amadou D, Habtemariam S. Natural wound healing and bioactive natural products. Phytopharmacol. 2013;4(3):532-560.

47. Abbas MM, Al-Rawi N, Abbas MA, Al-Khateeb I. Naringenin potentiated $\beta$-sitosterol healing effect on the scratch wound assay. Res Pharm Sci. 2019;14(6):566. doi:10.4103/1735-5362.272565
International Journal of Nanomedicine

\section{Publish your work in this journal}

The International Journal of Nanomedicine is an international, peerreviewed journal focusing on the application of nanotechnology in diagnostics, therapeutics, and drug delivery systems throughout the biomedical field. This journal is indexed on PubMed Central, MedLine, CAS, SciSearch ${ }^{\circledR}$, Current Contents ${ }^{\circledR} /$ Clinical Medicine,

\section{Dovepress}

Journal Citation Reports/Science Edition, EMBase, Scopus and the Elsevier Bibliographic databases. The manuscript management system is completely online and includes a very quick and fair peer-review system, which is all easy to use. Visit http://www.dovepress.com/ testimonials.php to read real quotes from published authors. 